\title{
NOTA A PROPÓSITO DE DUAS NOVAS ESTELAS FUNERÁRIAS ROMANAS PROCEDENTES DO NORDESTE DE PORTUGAL
}

\section{A NOTE ON TWO FUNERARY STELES FROM NORTHEASTERN PORTUGAL}

Armando Redentor

Universidade de Coimbra

aredentor@gmail.com

ORCID: 0000-0002-6459-3285

DOI: $10.1387 /$ veleia.18075

Resumo: A propósito de duas novas estelas funerárias romanas descobertas em Trás-osMontes Oriental, procedentes de Saldanha (Mogadouro) e de Gouveia (Alfândega da Fé), discutem-se os antropónimos Sula e Sulla do ponto de vista da sua representatividade nas províncias hispânicas e da sua origem linguística. A motivação para estas notas é a própria apresentaçáo das epígrafes, uma delas pela primeira vez dada a conhecer.

Palavras-chave: epigrafia funerária romana, antroponímia, Sula, Sulla, iconografia.

Abstract: This paper deals with the geographic distribution in the Hispanic provinces and with the linguistic origin of the anthroponyms Sula/Sulla, which have appeared in two new Roman funerary steles discovered in Eastern Trás-os-Montes, at Saldanha (Mogadouro) and Gouveia (Alfândega da Fé). The paper focuses on the epigraphs, one of which is made known for the first time.

Keywords: Roman funerary epigraphy, personal names, Sula, Sulla, iconography.

Recibido: 02-04-2013

Informado: 06-05-2013

Definitivo: 29-02-2016

\section{INTRODUÇÃO}

Foi descoberto, no ano de 2007, um novo documento epigráfico que incrementa o número de estelas funerárias conhecidas na freguesia transmontana de Saldanha. Tal como outras que foram sendo dadas a conhecer ao longo das últimas décadas, provém de um terreno de propriedade pública localmente designado de As Fontes, que se enquadra no contexto do arqueossítio conhecido 
como Lombo do Ouro. Este tem sido classificado na bibliografia arqueológica como um povoado aberto (Lemos 1993, IIa, 298, n. $\left.{ }^{\text {0 } 400)}\right)^{1}$.

Trata-se de uma estela dupla de mármore cujas circunstâncias de achado não permitiram que se exumasse íntegra. Apresenta fractura horizontal sensivelmente a meio da sua altura, que afecta, sobretudo, um dos registos que estruturam a face anterior. Como as restantes estelas funerárias procedentes do mesmo sítio, insere-se, pela sua organização ornamental, no que se tem designado de tipo Picote (Tranoy 1981, 349-350; Navarro 1998; Redentor 2002, 196-205). Tanto os elementos ornamentais que a compóem como o seu texto merecem detida atenção, por um lado, pela temática zoomórfica veiculada, por outro, pela antroponímia aí revelada, a qual, coincidentemente, pode ser posta em relaçáo com a de outra estela recentemente dada a conhecer (Vaz et alii 2012).

Estoutra provém de contexto geográfico também transmontano, mas um pouco mais ocíduo e meridional, separado do Planalto Mirandês pelo desfiladeiro do rio Sabor, correspondendo ao contínuo planáltico que se estende entre Alfândega da Fé e Adeganha, articulado pela serra de Gouveia, de caras à depressão da Vilariça. É precisamente do aglomerado situado na encosta sul desta serra, com a qual partilha o nome, que procede esta estela funerária de granito, incompleta, embora conservando a totalidade da cabeceira e do epitáfio. Encontrava-se em reaproveitamento na soleira de uma casa em ruínas, faltando o completo apuramento do contexto arqueológico a que se liga, talvez coincidente com o assentamento actual.

\section{As estelas funerárias de Saldanha e Gouveia}

Ambos os documentos entram na categoria das estelas de cabeceira semicircular, mas não têm correspondência directa do ponto de vista iconográfico, o que bem patenteia a sua organizaçáo decorativa. Afastam-se também na matéria do suporte.

No atinente à sua integração territorial (fig. 1), a proveniência de cada um deles relaciona-se com contextos distintos, como anteriormente se referiu. Inclusive, é possível que, do ponto de vista histórico, estes tenham correspondido a diferentes âmbitos provinciais, se for encarada a relação dos Banienses com as terras transmontanas meridionais à serra de Bornes, conforme têm sustentado diversos autores (Alarcão et alii 1990; Lemos 1993, IIa, 342-345 e 482-485; Redentor 2002 e 2008; Antunes \& Faria 2005, 256-257). O argumento epigráfico proporcionado pelo altar dedicado a Júpiter e à ciuitas Baniensisum (CIL II 2399) reforça este cenário (contra Silva 2011, 21).

${ }_{1} \mathrm{O}$ achado da estela foi protagonizado pelo presidente da Junta de Freguesia de Saldanha, Francisco Manuel Fernandes, aquando de uma mobilização de terreno realizada com uma retroescavadora. Agradecemos-lhe todas as facilidades concedidas para o estudo da peça e louvamos o interesse demonstrado na sua preservação. Agradecemos também todas as observaçôes e sugestôes de melhoria deste texto recebidas por parte dos avaliadores externos de Veleia. 


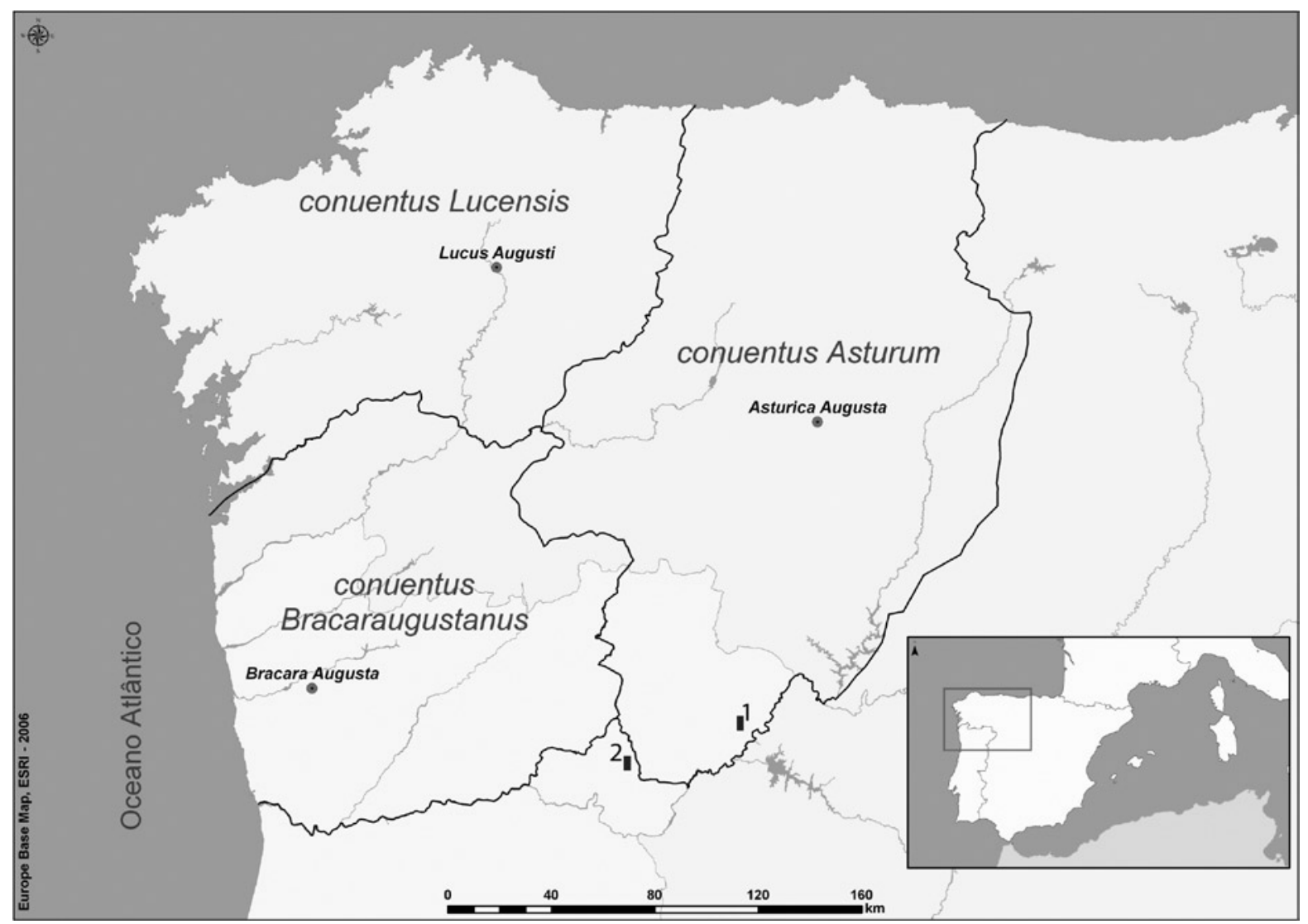

Figura I. Localização das estelas de Saldanha (1) e de Gouveia (2) (mapa adaptado de Redentor 2011)

\section{A estela de Saldanha (Mogadouro)}

A estela marmórea mogadourense é dupla $(94 \mathrm{~cm} \times 35 \mathrm{~cm} \times 5,5 \mathrm{~cm})$, apresentando a sua face anterior uma organização decorativa tripartida em cada um dos lados, simulando estrutura arquitectónica. As cabeceiras são preenchidas pelos ornatos habituais nos suportes do tipo Picote, integrados em campo rebaixado, com a forma de arco peraltado e de cantos reentrantes. Subjazem-lhes duplo par de cartelas incisas, de cantos com a mesma particularidade geométrica, decorrente da figuraçáo estrutural enunciada. E estas destinaram-se aos textos e às figuraçóes zoomórficas, as quais constituem marca relevante em termos tipológicos (fig. 2).

Em relevo plano, a ornamentaçáo das cabeceiras tem como motivo central a roda de raios curvos biselada sobre característica representação de pódio. A meia dúzia de raios que a estrutura toma uma orientaçáo sinistrorsa, nascendo eles de círculo central com ponto ao meio. Esta composiçáo aprecia-se mais claramente na cabeceira do lado direito, em virtude de se encontrar menos afectada por desgaste superficial, embora tenha sofrido danos no sector superior esquerdo devido a lascadura do rebordo da peça. O pódio é cingido superiormente por representação relevada de torques de extremidades em escócia, as quais se desenvolvem ao nível do eixo horizontal da roda. No lado direito, a extensão dos danos do rebordo da cabeceira afecta também este motivo. Par de esqua- 


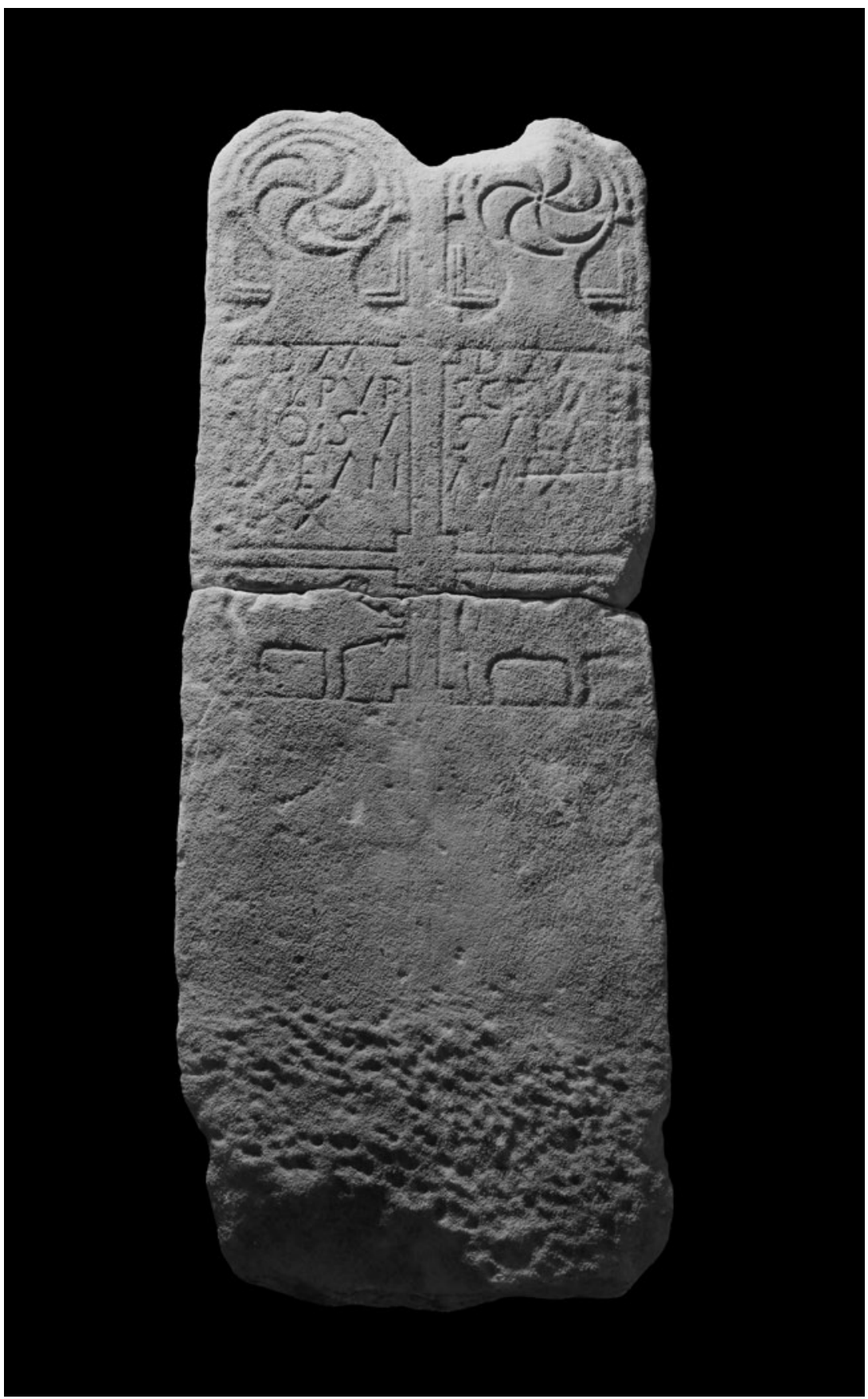

Figura 2. Estela de Saldanha (Mogadouro). Fotografia de Armando Redentor

dros, ou emblemas angulosos de figuração dupla, ladeiam o pódio de cada uma das cabeceiras, posicionando-se entre a base daquele e o limite do campo rebaixado, que lhe serve de guia para o desenvolvimento do segmento vertical, encaixando sobre os cantos reentrantes da base. 
As sequências duplas de cartelas incisas têm a clara individualizaçáo de cada uma delas como marca, ao não possuírem sulcos comuns. As que albergam os epitáfios apresentam desenvolvimento vertical $(16,5 \mathrm{~cm} \times 14,5 \mathrm{~cm}$ e $16,5 \mathrm{~cm} \times 14 \mathrm{~cm})$, adaptado às necessidades da gravação dos textos, ao passo que as que lhes subjazem surgem horizontalizadas. Estas incluem no seu interior figuraçôes incisas de porcos, em posição estática e voltados para a direita. Ambos os zoomorfos foram afectados pela fractura do suporte, que aconteceu sensivelmente ao nível da representaçáo da linha dorsal de cada um deles, lesando de sobremaneira o desenho da cabeça do figurado na cartela da direita, que também revela desgaste superficial.

A representação de cada um dos animais é bastante esquemática. $\mathrm{Na}$ da cartela do lado esquerdo foram introduzidos alguns pormenores, como a indicaçáo das orelhas, pontudas e erectas, e, ao nível do focinho, a marcaçáo da boca, reduzida a sulco horizontal, e do par de presas, apesar de em perspectiva distorcida. Estes aspectos parecem náo marcar a representaçáo zoomórfica da outra cartela, estando ausente, em ambas, a indicação do rabo ou a individualizaçáo, ao nível dianteiro e traseiro, das patas. $\mathrm{O}$ zoomorfo da cartela esquerda é claramente um javali. Mas não conseguimos ser tão peremptórios no respeitante ao da cartela da direita, não só por não se vislumbrar indicação das presas, mas também pelo desenho da cabeça, que no caso dos javalis (sus scrofa) tem uma configuração algo cónica, com chanfro recto e longo, e que no do porco doméstico (sus scrofa domesticus) é um tanto diferente, ao apresentar chanfro côncavo, mais curto e largo. O esquematismo aconselha prudência. É plausível que, neste caso, apenas se tenha pretendido representar um javali menos imponente, destituído da marca das suas presas. E isto náo nos parece ser alheio a uma linguagem simbólica que, decerto, teremos de pôr em relaçáo com as diferenças etárias dos defuntos e não não com o seu estatuto social. Quanto à iconografia zoomórfica e seu significado na epigrafia funerária transmontano-zamorana ocidental, é de salientar que as representaçôes patentes nesta estela corroboram a correspondência que, a partir do restante dossiê documental referente ao tema, se afigura verificar-se em relação ao género dos defuntos (Redentor 2003) ${ }^{2}$.

A extremidade do pé da estela apresenta-se um pouco mais estreita e sem alisamento, sendo simplesmente acabada a ponteiro, aspecto que se compreende pelo facto de estarmos a falar da parte que ficaria enterrada. $\mathrm{Na}$ face posterior, o acabamento, conservando marcas do desbaste, não é tão esmerado como o da principal, destacando-se o chanframento das arestas de cada um dos lados.

A estrutura dos epitáfios é bastante singela, resumindo-se à identificação dos indivíduos memoriados e à indicação da idade de falecimento, antecedidas pela dedicação aos Manes:

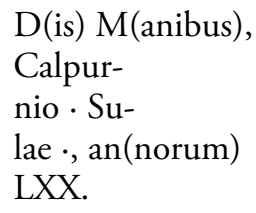

\author{
$\mathrm{D}$ (is) $\mathrm{M}$ (anibus), \\ Sceuae \\ Sulae, \\ an(norum) [.] XVI
}

Aos deuses Manes. A Ceva, de Sula, de 16 anos.
$2 \mathrm{O}$ estudo citado submeteu à crítica todos os suportes em causa, baseando-se numa avaliação da iconografia zoomórfica cruzada com a análise revisória dos epitáfios. Concluiu-se que, enquanto as figuraçóes de suínos estavam estreitamente ligadas aos defuntos do género masculino, ao género oposto se associavam maioritariamente representaçóes de fêmeas de cervídeo, e que nestas conexóes não interferiam as categorias etárias. Em face desta linha de correspondência com o género dos defuntos, afigurou-se plausível a interpretação das figuras zoomórficas associadas aos epitáfios como representaçóes simbólicas dos mesmos. 
Em ambas as cartelas, a fórmula $D . M$. surge enquadrada no espaço delimitado pelos cantos reentrantes superiores: seguindo um alinhamento à esquerda a da inscrição do lado direito; estando centrada a respeitante à do esquerdo. $\mathrm{O}$ alinhamento à esquerda marca, ainda, a paginação das restantes linhas em ambos os epitáfios.

Tanto uma como outra apresentam caracteres comuns de módulo contido e ductus que mantém alguma regularidade. Isto mesmo é perfeitamente ilustrado pelos DD de pança quase semicircular; pelos AA sem travessão, ainda que bem proporcionados; pelos MM largos, como que resultantes da uniáo de AA; pelos SS deitados para a frente ou os EE de barras curtas, embora a central náo regule sempre pelo centro da haste. Os CC aproximam-se mais de um arco ovalado do que semicircular. Os NN distinguem-se pela diferença de inclinação para a frente das suas hastes. Tanto o $\mathrm{P}$ como o R, apenas presentes na inscrição do lado esquerdo, apresentam panças miúdas, não chegando a fechar em baixo a do primeiro; o único $\mathrm{O}$, também compondo esta inscrição, é circular. Apenas é visível interpontuaçáo redonda na inscrição do lado esquerdo, separando palavras (l. 3 e 4 ), aspecto que nos leva a admitir a possibilidade de ter existido um ponto na derradeira linha da do lado direito, actualmente elidido por vinco que feriu a peça pelo meio das letras que a compóem, deixando apenas incólume a que a inicia.

$\mathrm{Na}$ cartela do lado esquerdo, a altura das letras é a seguinte: $1.1: 2,5 / 2,7 ; 1.2: 2,6 / 2,8 ; 1$. 3 : $3,1 / 3,2$; 1 . $4: 3,1 / 3,4 ; 1.5: 3 / 3,4(\mathrm{~cm})$. Os espaços interlineares regulam como segue: $1: 0,2 ; 2$ : $0,2 / 0,4 ; 3: 0,4 / 0,5 ; 4: 0,3(\mathrm{~cm})$. As margens (superior, inferior, esquerda e direita) têm as seguintes medidas: $0 ; 1,2 ; 0,5 / 2 ; 0,5 / 5,8(\mathrm{~cm})$. As medidas apuradas para as margens (superior, inferior, esquerda e direita) da cartela do lado direito denotam alguma diferença, em parte decorrente do facto de o texto aí gravado ter um número de linhas inferior: $0 ; 4,4 ; 0,2 / 0,5 ; 0,6 / 0,8(\mathrm{~cm})$. A altura das letras deste é aproximada à das da cartela do lado esquerdo: $1.1: 2,6 ; 1.2: 2,6 / 2,8 ; 1$. 3 : $3,3 / 3,5 ; 1.4: 3,3 / 3,5(\mathrm{~cm})$. O mesmo acontece no referente aos espaços interlineares: $1: 0,2 ; 2: 0,3$; 3: $0,4 / 0,5(\mathrm{~cm})$.

As observaçóes tipo-cronológicas realizadas por Navarro (1998) às estelas inseridas no tipo Picote permitem-nos algum conforto para sustentar uma cronologia para o suporte epigráfico em análise. Do ponto de vista tipológico, a peça tem cabimento no grupo II definido por aquela autora (ibidem, 184-187) em função de aspectos morfológicos e da estrutura da mensagem escrita, no qual não são infrequentes os exemplares de cabeceira dupla, podendo, inclusivamente, apontar-se como testemunho de continuidade técnico-estilística dos exemplares que reúne na oficina $\mathrm{D}$ do seu grupo I (ibidem, 183-184)3. No atinente à plástica, é de destacar a conciliação entre a lavra plana utilizada ao nível das cabeceiras e a delimitação incisa dos campos epigráficos e dos que contêm as representaçôes zoomórficas, em ambos os casos de cantos reentrantes ou, na formulação da autora, cruciformes. Quanto aos textos, a introdução da consagração aos Manes é um aspecto fun-

3 Talvez a estela dupla de Lucius Paternus e de um defunto de identificação truncada $\mathrm{No}$ [---], procedente de Aldeia Nova (Alves 1934, 31, n. ${ }^{\circ} 1=\mathrm{Na}-$ varro 1998,193 , grupo II, n.o 8 , erradamente atribuída a Duas Igrejas) possa considerar-se o exemplar desta evoluçáo mais próximo do ponto de partida, considerando a integraçáa da representaçáo de torques na cabeceira, embora falte o conhecimento da parte inferior às cartelas. Considerando a linha evolutiva enunciada, torna-se notória a verticalização dos campos epigráficos das peças atribuíveis ao segundo momento, o que em parte decorrerá do incremento apresentado pelas mensagens epigráficas. Ocorre-nos questionar se não será a oficina $\mathrm{C}$ deste grupo II a marcar essa evoluçáo, na qual a autora integra dois exemplares de cabeceira tripla. Olhamos a determinadas particularidades paleográficas e a resquícios dos elementos da cabeceira (emblemas angulosos e base da peanha) presentes numa delas, sendo que a evidente menor largura dos campos epigráficos se justificará pela necessidade de tripartição da largura do suporte. 
damental na individualização do grupo II, no qual se rastreiam defuntos socialmente diferenciados, mas denotando larga latinizaçáo onomástica, como se verifica no caso vertente. Deste modo, temos os meados dos séculos II e III como balizas cronológicas propostas para enquadrar as produçóes deste grupo. Isto considerando que nelas é adoptada a fórmula dedicatória aos Manes e se registam referências tanto a peregrini, condição jurídica que virá a desaparecer com a constitutio Antoniniana, como a ciues Romani, superando estas as primeiras.

A datação da epígrafe posicionamo-la por volta do início da terceira centúria, se dermos alguma importância ao critério paleográfico, regionalmente mais aceitável ao nível dos suportes marmóreos do que dos graníticos, e tendo em consideração o estatuto jurídico dos defuntos.

Ambos os defuntos memoriados nesta estela apresentam, ao que tudo indica, estruturas onomásticas peregrinas ${ }^{4}$. Ainda que para o defunto septuagenário se pudesse pensar que usufruiria da cidadania romana, considerando que o primeiro nome corresponde a um gentilício latino, o confronto com a identificação do defunto mais novo incita a que se depreenda que estes indivíduos estiveram unidos por relação fraternal. Identificam-se, assim, com idiónimo seguido de patronímico, que é o mesmo em ambas as nomenclaturas: Sula.

O gentilício latino Calpurnius (Solin \& Salomies 1988, 43; Abascal 1994, 104-106; OPEL 2, 25-26) é, a nível regional, testemunhado no Ocidente zamorano, nomeadamente nas localidades alistanas de Pino del Oro (CIL II 2614) e de Villalcampo (HAE 891), e na região de Bragança, em epitáfio referente a cavaleiro da ala II Flauia (EE IX 277 + ERRB 39). Não obstante, a sua utilização idionímica também não é inédita no contexto regional. Surge, já a nascente do Esla, num epitáfio gravado sobre escultura zoomórfica, em Muelas del Pan $(A E 1982,488)$.

O outro defunto, consideravelmente mais novo, ostenta o idiónimo Sceua. Este nome latino, de presença escassa na Hispânia e sem qualquer outra prova no Noroeste peninsular (CIL II 207; ECon 64; $A E$ 1993, 955; $A E 1977,416$, em variante monotongada como a da inscrição mogadourense) ${ }^{5}$, tem a particularidade de remeter, do ponto de vista semântico, para particularidade física referente à habilidade motora individual, enquanto traço ou qualidade relacionada com o desempenho de tarefas manuais ${ }^{6}$. É reconhecida a franca penetraçáo de onomástica latina relacionada com aspectos físicos entre a população livre e peregrina. Os exemplos peninsulares de Scaeua / Sceua acima elencados também são clara prova disso, pois apenas um caso (CIL II 207) não respeita a peregrini.

\section{A estela de Gouveia (Alfândega da Fé)}

Não se encontra completa a estela identificada no limiar da serra de Gouveia, em virtude do seu reaproveitamento numa habitação em ruínas situada na aldeia epónima ${ }^{7}$. Mas a parte em falta, correspondente ao pé do suporte, não deverá ter recebido qualquer lavor decorativo. Seguimos a caracterização que dela foi elaborada pelos seus editores (Vaz et alii 2012).

4 A questão da representação onomástica dos estatutos jurídicos deve a Chastagnol (u.g. 1990 e 1993) a formulação de critérios esclarecidos, em desenvolvimento e aplicação nas últimas décadas por muitos outros investigadores (cf. Grupo Mérida 2003; Ciprés 2006; Redentor 2011, I, 79-83; Dondin-Payre 2011).

5 Há, todavia, testemunho, no Ocidente zamorano, da forma afim $S c(a) e u u s$, em inscrição desaparecida de Figueruela de Arriba (Beça 1915, 95).
6 Kajanto $(1965,106)$ aceita que a forma antroponímica Scaeua, à semelhança de outras igualmente masculinas com a mesma particularidade sufixal, apresente sufixo formativo em - $a$ que pode ter tido origem etrusca e que assumiu conotaçáo pejorativa em latim. Em termos de significado, apesar do seu impacto ao nível da nobreza republicana, remete para a habilidade motora mais desenvolvida associada à mão esquerda (ibidem, 243).

7 A peça encontra-se presentemente depositada na sede da Junta de Freguesia de Gouveia. 
Trata-se de estela de cabeceira semicircular, elaborada sobre matéria granítica de grão médio a fino, com trabalho nas quatro faces $([79] \mathrm{cm} \times 45 \mathrm{~cm} \times 14,5 \mathrm{~cm})$. Apenas conserva íntegro o campo epigráfico, estando a cabeceira afectada por fractura no topo. Como referimos, abaixo da cartela não se vislumbra vestígio de qualquer outro registo, pelo que é possível que se completasse com pé apenas convenientemente acabado (fig. 3).

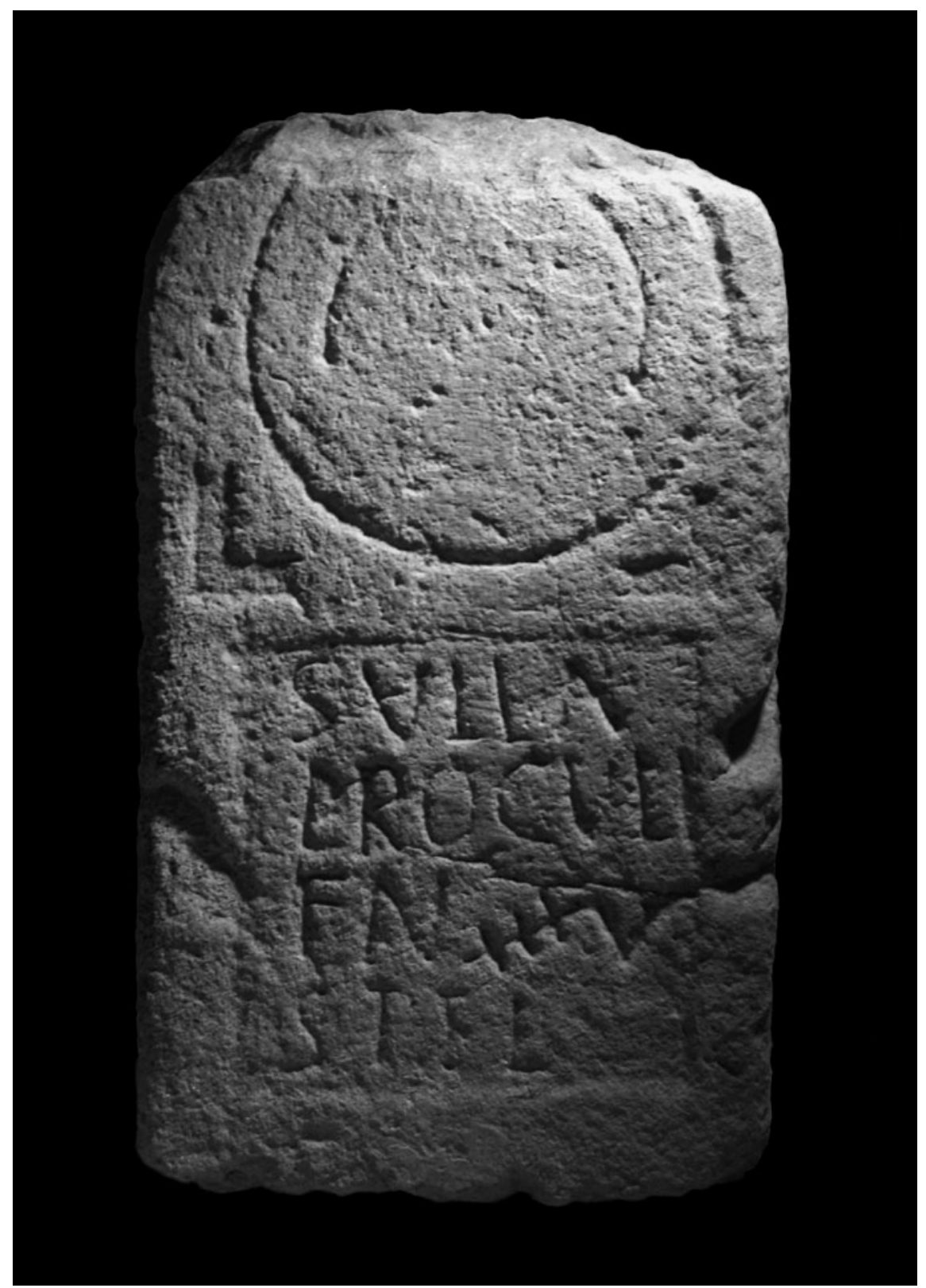

Figura 3. Estela de Gouveia (Alfândega da Fé). Fotografia de Sérgio Pereira 
A ornamentação da peça, cingida à cabeceira, é marcada por um círculo insculpido contendo no seu interior um motivo ultra-semicircular; este, reduzido a simples linha obtida pela mesma técnica e com as extremidades marcadas por pontos ligeiramente mais largos e profundos, sugere a figuração de torques. Como acima se ilustra, a representação deste elemento de prestígio tem paralelo na epigrafia transmontano-zamorana ocidental da época romana, nomeadamente associado ao elenco ornamental das peças integráveis no designado tipo Picote. A acompanhar a metade inferior do círculo, par de esquadros de extremidades bífidas rebaixados. Logo abaixo, surge, também em rebaixe, o campo epigráfico de formato quadrangular $(32,5 \mathrm{~cm} \times 32,5 \mathrm{~cm})$.

O delineamento de ambos os registos sobre a face da estela denota um trabalho preparatório fraco. Atente-se na diferença de largura, ainda que ligeira, dos rebordos laterais criados pelo rebaixe da cartela ou no deslocamento para a direita, em relaçáo ao eixo central da face anterior do suporte, do círculo da cabeceira. Neste último caso, mesmo registando que no centro do círculo se observa vestígio de um ponto que, decerto, remeterá para marcação, prévia à execução biselada, dos elementos circulares, com auxílio de compasso ou de técnica expedita que o substituísse.

As faces laterais apresentam acabamento idêntico ao da face anterior, ao passo que a posterior não recebeu mais que o desbaste realizado em sentido vertical.

O epitáfio é bastante simples. Distancia-se, quanto à estrutura, dos da inscrição anterior pela ausência da dedicatória aos deuses Manes e por incluir uma fórmula de clausura reduzida a uma sequência de quatro iniciais:

$$
\begin{aligned}
& \text { Sulla } \\
& \text { Proculi } \\
& \mathrm{f}(\mathrm{ilius}) \text {, 'an'(norum) 'XXX'V } \\
& \mathrm{s}(\mathrm{it}) \cdot \mathrm{t}(\mathrm{ibi}) \cdot \mathrm{t}(\text { erra }) \cdot 1(\text { euis }) \text {. } \\
& \text { Sula, filho de Próculo, de } 35 \text { anos, } \\
& \text { que a terra te seja leve. }
\end{aligned}
$$

A paginação e, sobretudo, o ductus dos caracteres denotam irregularidade, embora tenha sido alcançado o efeito geral de alinhamento à esquerda, com a particularidade de a última linha ter início desregulado das restantes e de se verificar que a 1. 2, mais extensa, acaba por alcançar o limite direito da cartela. A gravação é pouco aferida, denotando tibieza na execução, tendo produzido caracteres comuns marcados pela tendência para o alongamento. Destacam-se a brevidade das barras dos LL e TT, a redução dos travessóes, que apenas se ligam a uma das pernas dos $\mathrm{AA}$, o desenho ovalado do $\mathrm{O}$ e as panças dos $\mathrm{P}$ e R, apesar de substancialmente diferentes, pois enquanto a do primeiro se apresenta reduzida à metade superior, a do segundo é fechada, nascendo na sua ligaçáo à haste a perna oblíqua que completa o caractere. Podemos ainda apontar a particularidade do F, de barras de larguras iguais, mais desenvolvidas do que as que se observam nos LL e TT, mas estando a inferior acima do meio da haste. Todavia, o que chama mais a atenção é o recurso a um nexo numérico, infrequente na epigrafia regional, antecedido por um outro bastante usual para a abreviatura an(norum). O primeiro é triplo, ligando-se os XXX ao vértice do traço esquerdo do $\mathrm{V}$ por haste ascendente comum aos três.

$\mathrm{O}$ recurso à interpontuaçáo parece ocorrer apenas associado às siglas, nomeadamente a seguir ao $\mathrm{F}$ do aposto filius, neste caso sob a sua barra inferior, e, verosimilmente, na separação de cada uma das iniciais da fórmula final, posicionada sensivelmente a meio da altura das letras.

A altura das letras é a seguinte: 1. 1: 5,5/6; 1. 2: 6/7; 1. 3: 6,4/7 (nexo = 9,5); 1. 4: 5,5/6 (cm). Os espaços interlineares são variáveis: $1: 1,3 / 1,7 ; 2: 1,8 / 3,6 ; 3: 1,4 / 2(\mathrm{~cm})$. As margens (superior, inferior, esquerda e direita) são de: 1,$8 ; 1,8 ; 3,5 ; 0 / 9,5(\mathrm{~cm})$. 
Considerou-se o monumento funerário datável por volta da primeira metade da segunda centúria, tendo em conta o registo do nome do defunto em nominativo associado à fórmula final $s$. t. t. l. apartada de h. s. e., bem como a ausência de dedicatória aos Manes e, ainda, a paleografia e as técnicas aplicadas à execuçáo dos registos que estruturam a face anterior da estela. Neste último plano, é destacável a conciliação da incisão com o rebaixe, aspecto significativo no cotejo com a evolução técnico-estilística associada aos exemplares do tipo Picote (Navarro 1998), com o qual é comparável o motivo ornamental da cabeceira, tal como se mencionou.

O defunto é um peregrino, conforme indica a estrutura onomástica composta pelo idiónimo Sulla associado ao patronímico Proculus em genitivo, seguido da inicial do aposto que clarifica a relaçáo familiar. E se este último nome tem forte distribuição na Hispânia (Abascal 1994, 471-472; OPEL 3, 166-167), com representatividade assinalável na sua parte ocidental (Tranoy 1981, 364; Grupo Mérida 2003, 272-273, mapa 247), onde granjeia boa penetração nos meios indígenas, a documentação do antropónimo que ostenta o defunto é bastante mais contida, como de seguida analisaremos.

\section{As Formas ANTroponímicas SVLA / SVLLA E O SEU ENQUADRAMENTO LINGUístico}

Em face dos textos proporcionados por estas duas epígrafes, uma breve nota se impóe. Respeita à onomástica presente nos epitáfios em questão, concretamente no que concerne às formas Sula / Sulla e à sua origem linguística, considerando a falta de unanimidade de posicionamentos por parte da investigaçáo quanto ao assunto.

No mais recente estudo sobre antroponímia indígena atinente ao contexto lusitano, as formas Sula / Sulla são descartadas (Vallejo 2005, 508), advogando-se que a presença de Sulla / Sylla / Sula em Roma, ultrapassando as duas centenas de casos, bem como a existência de um gentilício Sullius demonstrariam claramente a influência latina, aduzindo-se, ainda, que a maioria dos exemplos hispânicos se incluem em estruturas onomásticas romanas, apesar das dúvidas apontadas relativamente a duas inscriçóes em concreto ( $A E$ 1967, 157 e ERClu 60). Aí se regista um predomínio das duas grafias acima apontadas, para além de duas outras formas singulares em contexto peninsular: Sullia, gentilício documentado em ara bracarense (EE VIII 123), e Sulo, cognome comprovado em Tarraco (CIL II 4404 + RIT 665). Quanto à distribuição destas, verifica-se que a geminada tem clara preponderância em território lusitano (3 casos contra 1$)$, contrariamente à simples, que surge mais bem documentada na Hispania citerior, nomeadamente na área burgalesa, onde também se situava o único exemplo da forma geminada alheio ao contexto ocidental.

No que respeita às nomenclaturas aí arroladas, há que fazer alguns reparos no atinente à sua interpretação do ponto de vista estrutural, conforme decorre dos quadros 1 e 2 , nos quais elencamos as estruturas onomásticas registadas nas províncias hispânicas que contêm os elementos antroponímicos em causa.

\begin{tabular}{|c|c|c|c|}
\hline Noмe & REFERÊNCIA & Proveniência & \\
\hline Calpurnius Sulae / Sceva Sulae & & Hcit., Mogadouro, Bragança & 1 \\
\hline Eladua At[---] Antia[---] Sulae [f:? ---] & ERClu $60+H E p 2,123$ & Hcit., Clunia, Burgos & 2 \\
\hline Q(uintus) Sula & $A E 1985,590+C I R P B 562$ & Hcit., San Vicente del Valle, Burgos & 3 \\
\hline Flaccus Sulae filius & CIL II 5326 & Lus., Caesarobriga, Toledo & 4 \\
\hline
\end{tabular}

QuAdro I. Sula 
Começando pelas que contêm a forma não geminada, aponta-se, no estudo citado, a estrutura onomástica $Q$ (uintus) Sula $[M]$ arcele referente a inscrição de San Vicente del Valle (AE 1985, $590+C I R P B$ 562). Cremos, todavia, que a sequência contém os nomes do dedicante e da defunta homenageada no epitáfio. Entendendo-se a abreviatura como relativa ao prenome romano Quintus, estar-se-á, verosimilmente, em face de nomenclatura peregrina. Por esta particularidade da abreviatura prenominal, constituirá variante de um tipo de estrutura onomástica que tem como distintivo ser formado por dois idiónimos, em geral seguidos de filiação, o qual se encontra perfeitamente documentado na área celtibérica (Navarro et alii 2011, 112-117). Por outro lado, a incompletude da inscrição relativa a Clunia $(E R C l u 60+H E p$ 2, 123) pode levantar algumas hesitaçôes interpretativas, mas afigura-se tratar-se de estrutura onomástica deste mesmo tipo, isto é, com duplo idiónimo, complementado por genitivo de plural e filiação ou apenas por filiação igual-

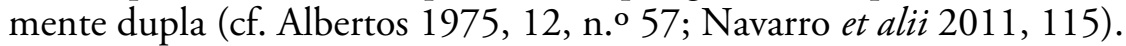

Também o registo epigráfico toledano (CIL II 5326) não oferece dúvida quanto ao estatuto jurídico do indivíduo, considerando que se está em presença de estrutura onomástica constituída por idiónimo e patronímico.

Assim, verifica-se que, neste elenco, a utilização da forma antroponímica Sula se associa exclusivamente a nomenclaturas vinculadas a peregrini e que predominantemente reveste a função de patronímico.

\begin{tabular}{|c|c|c|c|}
\hline Nome & REFERÊNCIA & ProveniÊNCIA & \\
\hline Sulla Proculif. & & Lus., Alfândega da Fé, Bragança & 1 \\
\hline Sulla Arcif. & $A E 1967,157$ & Lus., Idanha-a-Velha, Castelo Branco & 2 \\
\hline S[u]lla Lucrion[is] & $A E$ 1990, 508 & Lus., Idanha-a-Velha, Castelo Branco & 3 \\
\hline Tongius Sulla $[\mathrm{e}] f$. & CIL II 757 & Lus., Alcántara, Cáceres & 4 \\
\hline Sullinus Sullae & $H E p 7,526$ & Hcit., Oimbra, Orense & 5 \\
\hline G. Sempronius Q(uirina tribu?) Sulla & CIRPB 30 & Hcit., Belorado, Burgos & 6 \\
\hline L. Samnius Sulla & CIL II 1044 & Baet., Castilblanco de los Arroyos, Sevilla & 7 \\
\hline
\end{tabular}

QuADro 2. Sulla

No que concerne à forma Sulla, apenas ressalta da documentação um caso problemático decorrente da necessidade de se estabelecer uma interpretação coerente do texto, infelizmente incompleto, gravado em placa egitaniense. Esta situação levou, inclusive, a que se tivesse sugerido a restituição [T] ulla (AE 1990, 508) em substituição da forma em causa, embora nos pareça menos apropriada: quer por existir esta alternativa já firmada em solo egitaniense —embora também o antropónimo feminino alvitrado se tenha recentemente documentado em território lusitano ( $A E$ 2006, 618)—, quer, sobretudo, pela estrutura textual. Afigura-se-nos pouco intuitiva a interpretação do texto, que se tem, ainda, referido como contendo um estranho vocábulo, [.] OROSVCELAEBVLO, olhado como hipotética alusão a uma função técnico-profissional, se não administrativa (CôrteReal \& Encarnação 1990) ${ }^{8}$. No entanto, em face da incompletude do suporte à esquerda e à direita,

8 A leitura publicada pelos editores da inscrição, considerando a inclusão do homenageado em meio servil, é a seguinte: [S] ulla Lucrio / [---]orosucelaebulo /
[La]nciensi Oppidan[o] / uxor f(aciendum) c(urauit). Seguem-na integralmente Ana Paula Ferreira (2004, 140 , n. $\left.{ }^{\circ} 131\right)$ e Ana Sá $\left(2007,86\right.$, n. $\left.{ }^{\circ} 104\right)$. 
cremos plausível que a nomenclatura em causa seja de tipo peregrino, com o idiónimo seguido de patronímico em genitivo: $[S]$ ulla Lucrion $[i s]^{9}$.

Apenas testemunhos exteriores ao âmbito lusitano, localizados no conuentus Cluniensis (CIRPB 30) e no Hispalensis (CIL II 1044), documentam nomenclaturas quiritárias, a primeira com plausível indicação de tribo (Wiegels 1985, 147; Andreu 2004, 346).

Num terceiro documento externo às terras lusitanas (HEp 7, 526), localizado a norte do Douro, em território conventual bracaraugustano, surge o antropónimo associado a estrutura onomástica peregrina, denunciada pelo facto de o idiónimo a que o genitivo do nome Sulla se associa ser precisamente uma forma afim derivada em -inus, apesar de ter sido proposta a sua segmentaçáo duonominal ${ }^{10}$. De tipo peregrino são ainda as restantes estruturas onomásticas que incluem a forma Sulla, ambas associadas ao território lusitano (CIL II 757 e $A E$ 1967, 157), à semelhança da egitaniense que antes comentámos e da presente no documento alfandeguense que aqui também trouxemos.

Se o cenário de alguma compartimentação geográfica das duas formas que parece desenhar-se (fig. 4) nos deve deixar alerta quanto à possibilidade de se estar perante a evidência de uma base antroponímica indígena, a avaliação da sua inserção nas fórmulas onomásticas parece revelar-se mais insinuante a este propósito. Das doze nomenclaturas associadas a indivíduos de condição livre, dez são efectivamente peregrinas, sobrando apenas duas quiritárias, sendo que ambas integram a forma geminada em função cognominal. Nas estruturas onomásticas peregrinas, à documentação predominante da forma simples na função patronímica (4 casos contra 1), há a contrapor que a geminada se afirma na função de idiónimo, sem que deixe de se registar como patronímico (3 casos contra 2).

9 No final da 1.1 é ainda observável o arranque da haste esquerda do N. Em face das dificuldades colocadas pelo texto, acentuadas pela falta das extremidades das três primeiras linhas, não enjeitamos que o nome que abre o epitáfio seja o do dedicante, implicando esta hipótese interpretativa, com a vantagem de contornar o inusitado nome proposto para a segunda regra, que se assuma uma discordância gramatical no termo uxor, atribuível a um erro de gravação consistente na náo marcação da desinência do dativo: $[S]$ ulla Lucrion[is] / [.] oro Sucelae Bulc[ae f(iliae)?] / [La]nciensi Oppidan[ae] / uxor<i> f(aciendum) c(urauit). As separaçôes que fazemos de diferentes vocábulos na 1.2 têm sobretudo a ver com razóes onomásticas. Por um lado, apesar de apenas encontrar paralelo fora do contexto hispânico, a forma antroponímica Sucela tem ocorrência noutras províncias europeias $(C I L \mathrm{~V}$ 1790; CIL III 4770 e 5463). Por outro, inscriçôes de Clunia (= Peñalba del Castro) $(A E 1920,80+1987,613 c)$ e Sabrosa $(A E 1982,568+A E 1983,585)$ dão-nos a conhecer o nome Bulca, de tema em -a e -apesar das reticências de Vallejo (2008, 147, n. 26) — género masculino, no caso da inscrição lusa na grafia Bulcai, decerto dativo, olhando ao restante conteúdo do texto, sendo, à partida, de rejeitar a leitura Buloni sugerida em sua substituição ( $A E$ 1982, 568; Abascal 1994 , 305), ainda que fosse desejável a realização de nova autópsia à epígrafe, actualmente em paradeiro desconhecido. Os caracteres mais à esquerda nessa mesma 1.2 poderão corresponder a um ablativo de origem relativo ao dedicante, embora possa objectar-se pelo facto de competir com a denominação da defunta, o que, contudo, deve ser relativizado quando a paginaçáo, assim sendo, primaria pelo destaque do marido viúvo.

Agradecemos a José Cristóvão a pormenorizada informação prestada acerca da epígrafe e a propósito das questốes que lhe colocámos com respeito à conservação do texto.

${ }_{10}$ A leitura efectuada por Rodríguez Colmenero (AquaeFlauiae ${ }^{2} 58$ ) associa o patronímico a uma estrutura onomástica duonominal, S(ulpicius) Velinus, embora, à luz da documentação fotográfica publicada, nos pareça mais coerente a leitura Sullinus Sullae, tendo também em conta que a forma Velinus não parece documentar-se no âmbito peninsular (Abascal 1994; OPEL 4). 


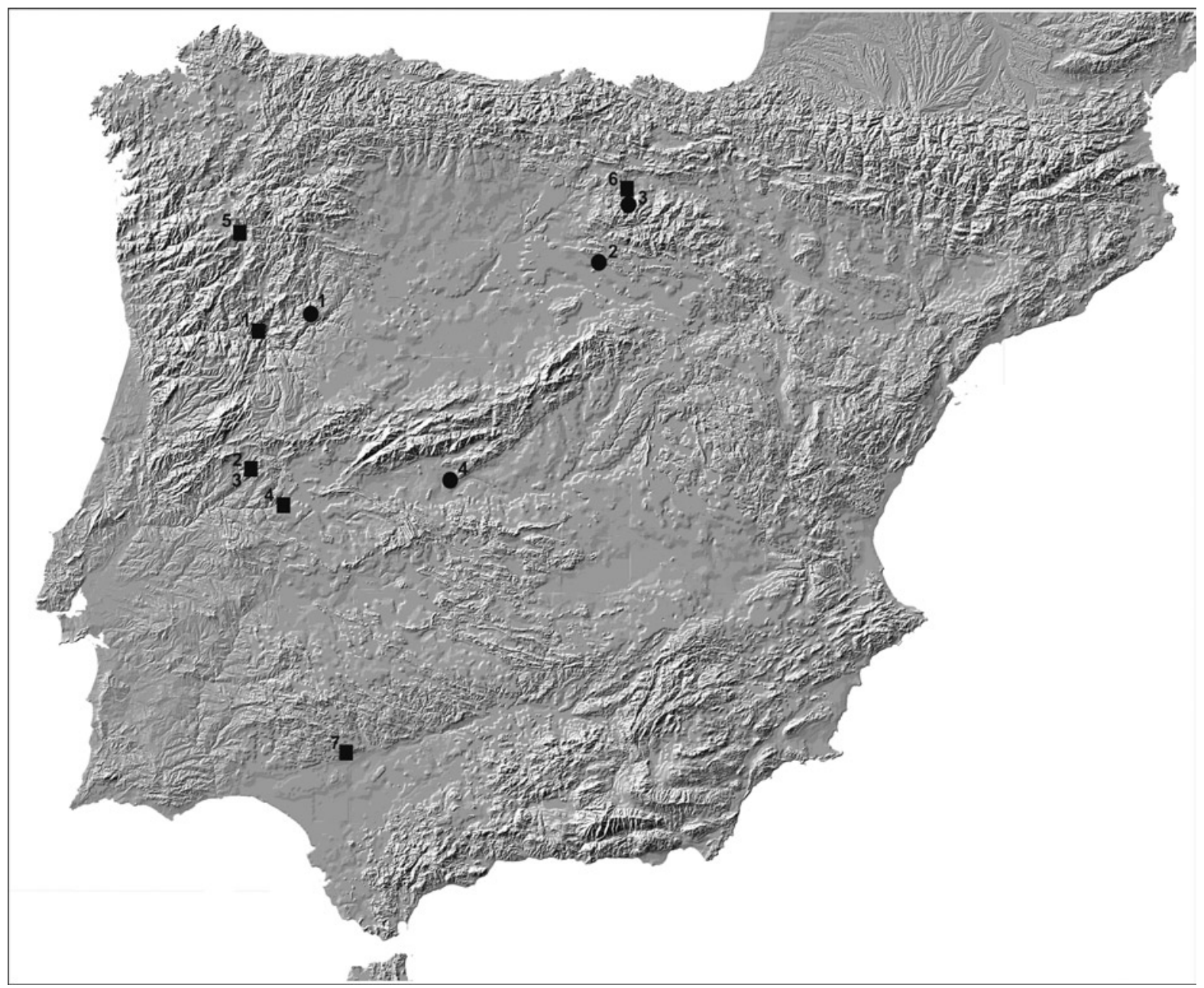

Figura 4. Distribuição dos antropónimos Sula (•) e Sulla (ロ) na Hispânia. A numeração tem correspondência com a dos quadros 1 e 2

O estado actual da documentação incita a que, prudentemente, não se afaste a ideia de relação com o fundo antroponímico indígena, apesar de, nas nomenclaturas peregrinas em causa, a relação se efectivar maioritariamente com formas antroponímicas alóctones e de a forma geminada ter evidente inserção no onomástico latino. Por ora, os exemplos de formas geminadas ultrapassam os de formas simples, estando sobretudo documentados no âmbito lusitano, com prolongamentos aos espaços galaico, celtibérico e bético, sendo de admitir, até por esta evidência hispânica de concomitância de ambas as formas, a existência de um elemento antroponímico original ainda que decerto incrementado pela via latina ${ }^{11}$, à qual habitualmente se imputa a presença da forma antroponímica

11 A este propósito parece-nos importante destacar com Vallejo $(2005,585)$ que, ao nível da onomástica indígena do âmbito lusitano, a geminação - ll- não aparenta grande desenvolvimento, contrariamente ao que acontece ao nível latino e gaulês. Já Albertos (1966, 293) considerava que o valor diminutivo que por vezes tomavam as formas geminadas com - $l l$ - nem sempre era originário, sendo imputado pelo mesmo uso em latim. 
em causa noutras partes do império. Apesar de a distribuição hispânica ainda se mostrar mais restrita do que a registada em Roma (cf. Vallejo 2005,508$)^{12}$, não se descarta que o esboço que a documentação apresenta espelhe em boa parte o resultado de um fenómeno de homonímia — pelo menos em termos fonológicos- entre formas dos patrimónios antroponímicos autóctone e latino. E não há que olvidar que a própria forma cognominal latina, que vemos aventada pela associação a nomes incontornáveis da história republicana, nomeadamente associados à gens Cornelia ${ }^{13}$, é provavelmente de origem etrusca (Kajanto 1965, 106).

Em comentário à inscrição toledana que contém a forma Sula, Albertos $(1966,213)$, realçando a existência do radical, quer dentro, quer fora da Hispânia, propôs a relaçáo com o indo-europeu *sul- «sol» (IEW, 881). Na sua esteira, também Abascal $(1994,517)$ assentou diferenciar entre as formas Sula e Sulla, considerando latina, como Solin e Salomies (1988, 409), esta última.

\section{Conclusão}

O património epigráfico transmontano vê-se enriquecido por mais um par de documentos de carácter funerário que, apesar de procederem de contextos geográficos distintos, talvez mesmo administrativamente separados na Antiguidade, nos parecem conservar afinidades iconográficas ao nível das representaçóes de torques que se encontram nas cabeceiras. Se o registo deste objecto presente na estela de Gouveia, pela sua extrema simplicidade, se pode prestar a alguma confusão com um crescente, não cremos que deva olhar-se como símbolo da própria lua (Navascués 1963, 172; Marco 1978, 59), pois a importância e simbolismo do objecto no mundo indígena seriam suficientes para que se elegesse como marca de distinção e dignidade, remetendo para a exaltação ou mesmo heroificação do defunto (Redentor 2002, 242).

Do ponto de vista iconográfico, estes dois documentos continuam a mostrar que, mais do que adoptar cabalmente modelos alóctones e perfeitamente romanos, a sociedade indígena soube estabelecer uma síntese simbólica entre a sua herança e a novidade introduzida pelos novos tempos. O recurso à representação simbólica por intermédio de figuração animal associada à fauna da floresta temperada, que difere em função do género dos defuntos, é uma particularidade da epigrafia transmontano-zamorana ocidental e que aflora especialmente nas estelas do designado tipo Picote.

Essa conciliação é também visível ao nível onomástico, manejando a população indígena, peregrina ou naturalizada, nomes próprios com origens linguísticas diferenciadas, os que lhes transmitiram os antepassados e os que são latinos. Nesta relaçáo dual há nomes, como provavelmente Sula / Sulla, que terão feito a ponte entre os dois mundos, não soando estranhos a indígenas quando ostentados por indivíduos de origem itálica, nem a romanos quando percepcionados entre a tradição nativa. O seu carácter homofónico decerto confunde mais os que hoje tentam perscrutar o passado por essa via.

\footnotetext{
12 Não serão demasiadamente acusadas as diferenças entre a distribuição da Gallia Cisalpina (Regiones IX, X e XI Italiae) e a das províncias hispânicas; é, todavia, residual noutras províncias europeias, onde apenas consta a forma antroponímica geminada (OPEL 4, 98).
}

\footnotetext{
13 Destaque maior para o ditador L. Cornelius Sulla Felix (c. 138 a. C.-78 a. C), mas também para o seu sobrinho P. Cornelius Sulla (?-45 a. C.). Como é conhecido, este último viu-se implicado na conjuraçáo de Catilina, beneficiando da defesa realizada por Cícero (Cic., Sull.); veio a ser partidário de César na segunda Guerra Civil, exercendo o comando militar sob suas ordens na batalha de Farsália.
} 


\section{BibLIOGRAFIA}

Abascal Palazón, J.M., 1994, Los nombres personales en las inscripciones latinas de Hispania, [Anejos de Antigüedad y Cristianismo 2], Murcia: Universidad, Secretariado de Publicaciones, Madrid: Universidad Complutense.

$A E=$ L'Année Epigraphique, Paris: CNRS-Université de Paris I.

Alarcão, J., Gorges, J.-G., Mantas, V., Salinas de Frías, M., Sillières, P., Tranoy, A., 1990, «Propositions pour un nouveau tracé des limites anciennes de la Lusitanie romaine», in: Les Villes de Lusitanie romaine: hiérarchies et territoires (Table ronde internationale du CNRS-alence, 8-9 décembre 1988), [Collection de la Maison des pays ibériques 42], Paris: Éd. du Centre Nacional de la Recherche Scientifique, 317-329.

Albertos Firmat, M.L., 1966, La onomástica personal primitiva de Hispania: Tarraconense y Bética, [Theses et studia philologica salmanticensia 13], Salamanca: Consejo Superior de Investigaciones Científicas.

—, 1975, Organizaciones suprafamiliares en la Hispania antigua, [Studia Archaeologica 37], Santiago de Compostela: Departamento de Prehistoria y Arqueología, Faculdad de Historia y Geografía, Universidad, Valladolid: Departamento de Prehistoria y Arqueología, Faculdad de Filosofía y Letras, Universidad.

Alföldy, G., 1975, Die römischen inschriften von Tarraco, [Madrider Forschungen 10], Berlin: W. de Gruyter.

Alves, F.M., 1934, Memórias arqueológico-históricas do distrito de Bragança 9: arqueologia, etnografia e arte, Porto: Tip. da Emprêsa Guedes.

Andreu Pintado, J., 2004, "Apuntes sobre la Quirina tribus y la municipalización flavia de Hispania», Revista Portuguesa de Arqueologia 7:1, 343-364.

Antunes, J.V., Faria, P. B., 2005, "O povoamento antigo», in: Almeida, C.A.B. (coord.), História do Douro e do Vinho do Porto 1: História Antiga da Região Duriense, Porto: GEHVID-Afrontamento, 188283.

AquaeFlauiae ${ }^{2}=$ RodríGuez 1997.

BEÇA, C., 1915, «Estudos arqueológicos do major Celestino Beça: a estrada militar romana de Braga a Astorga por Bragança com várias notícias de antiguidades referentes a esta região» [publicação póstuma realizada pelo Pe. Francisco Manuel Alves], O Archeologo Português, 20, 74-103.

Cicero, M.T., 1913-1921, The Orations of Marcus Tullius Cicero, trans. Yonge, C.D., London: G. Bell and Sons.

$C I L=$ Corpus Inscriptionum Latinarum, consilio et autoritate Academiae litterarum regiae Borussicae editum, Berolini, 1863-.

CIL II = HÜBNER 1869 e 1892.

Ciprés, P., 2006, «La onomástica de las inscripciones romanas del País Vasco: estructura del nombre personal y estatuto jurídico», Veleia 23, 85-128.

CIRPB = Crespo, Alonso, 2000.

Chastagnol, A., 1990, «L'onomastique de type pérégrin dans les cités de la Gaule Narbonnaise», Mélanges de l'École Française de Rome 102:2, 573-593.

—, 1993, "Considérations sur les gentilices des pérégrins naturalisés romains dans les Gaules et les provinces des Alpes», Bulletin de la Société Nationale des Antiquaires de France, 167-183.

Côrte-Real, A., Encarnação, J. D’, 1990, «Homenagem a Sula Lucrião (Aegitania)», Ficheiro Epigráfico $34,{ }^{\circ}{ }^{\circ} 153$.

Crespo Ortiz de Zárate, S., Alonso Ávila, A., 2000, Corpus de inscripciones romanas de la Provincia de Burgos: fuentes epigráficas para la historia social de Hispania romana, Valladolid: autores.

Dondin-Payre, M., 2011, «Introduction», in: Dondin-Payre, M. (éd.), Les noms de personnes dans l'Empire romain, [Scripta Antiqua 36], Bordeaux: Ausonius, 13-36.

ECON = ETIENNE et alii 1976 .

$E E \mathrm{VIII}=$ HÜBNER 1899. 
EE IX = HÜBNER 1903.

Étienne, R., Fabre, G., Lévêque, P. e M., 1976, Epigraphie et Sculpture, [Fouilles de Conimbriga 2], Paris: Boccard.

$E R C l u=$ PALOL, VILELLA, 1987.

$E R R B=$ REDENTOR 2002.

FERreira, A.P.R., 2004, Epigrafia funerária romana da Beira interior: inovação ou continuidade?, [Trabalhos de Arqueologia 34], Lisboa: Instituto Português de Arqueologia

Grupo Mérida, 2003, Atlas antroponímico de la Lusitania romana, Mérida: Fundación de Estudios Romanos, Bordéus: Ausonius Éditions.

HAE = Hispania Antiqua Epigraphica: suplemento anual de Archivo Español de Arqueologia, Madrid: Consejo Superior de Investigaciones Científicas.

$H E P=$ Hispania Epigraphica, Madrid: Archivo Epigráfico de Hispania, Universidad Complutense.

HüBner, E., 1869, Inscriptiones Hispaniae Latinae. Corpus Inscriptionum Latinarum II, Berolini: apud Georgium Reimerum.

—, 1892, Inscriptiones Hispaniae Latinae: Supplementum. Corpus Inscriptionum Latinarum II, Berolini: apud Georgium Reimerum.

—, 1899, «Additamenta noua ad corporis uolumen II», Ephemeris Epigraphica 8, 351-528.

—, 1903, «Additamenta noua ad corporis uolumen II», Ephemeris Epigraphica 9, 12-185.

$I E W=$ POKORNY 1959.

Kajanto, I., 1965, The Latin Cognomina, [Commentationes Humanarum Litterarum. Societas Scientiarum Fennica 36, 2], Helsinki: Keskuskirjapaino [2.a edição, Roma: Giorgio Bretschneider, 1982].

Lemos, F.S., 1993, O povoamento romano de Trás-os-Montes Oriental, Braga: [s. n.] (tese de Doutoramento apresentada à Universidade do Minho), 2 vols.

LörIncz, B., 1999, Onomasticon Prouinciarum Europae Latinarum 2: Cabalicius-Ixus, Wien: Forschungsgesellschaft Wiener Stadtarchäologie.

—, 2000, Onomasticon Prouinciarum Europae Latinarum 3: Labareus-Pythea, Wien: Forschungsgesellschaft Wiener Stadtarchäologie.

—, 2002, Onomasticon Prouinciarum Europae Latinarum 4: Quadratia-Zures, Wien: Forschungsgesellschaft Wiener Stadtarchäologie.

Marco Simón, F., 1978, Las estelas decoradas de los conventos caesarangustano y cluniense, [Caesaraugusta 4344, Publicación de la Institución «Fernando El Católico» 659], Zaragoza: Institución «Fernando El Católico".

NavÁscuÉs, J.M., 1963, "Caracteres externos de las antiguas inscripciones salmantinas. Los epitafios de la zona occidental», Boletín de la Real Academia de la Historia 152, 159-223.

Navarro Caballero, M., 1998, «Las estelas en brecha de Santo Adrião: observaciones tipológico-cronológicas», Boletín del Seminario de Estudios de Arte y Arqueología 64, 175-206.

Navarro Caballero, M., Gorrochategui, J., Vallejo, J.M., 2011, «L'onomastique des Celtibères: de la denomination indigène à la denomination romaine», in: Dondin-Payre, M. (éd.), Les noms de personnes dans l'Empire romain, [Scripta Antiqua 36], Bordeaux: Ausonius, 89-175.

OPEL 2 = LÖRINCZ 1999.

OPEL 3 = LÖRINCZ 2000.

OPEL 4 = LÖRINCZ 2002.

Palol Salellas, P., Vilella Masana, J., 1987, Clunia II: la epigrafía de Clunia, Madrid: Ministerio de Cultura.

PокоRny, J., 1959, Indogermanisches etymologisches Wörterbuch, Bern-München: Francke Verlag.

Redentor, A., 2002, Epigrafia romana da região de Bragança, [Trabalhos de Arqueologia 24], Lisboa: Instituto Português de Arqueologia.

—, 2003, «Representaçóes zoomórficas na epigrafia funerária transmontano-zamorana ocidental da época romana», in: Congresso Internacional de Arqueologia Iconográfica e Simbólica (Meda e Vale do Côa, 20-25 de abril 2002): livro de actas, [Condeixa-a-Velha]: Liga de Amigos de Conimbriga, 163-199. 
—, 2008, «Panorama da teonímia pré-romana em Trás-os-Montes Oriental», in: Encarnação, J. d’(coord.), Divindades indígenas em análise: actas do VII workshop F.E.R.C.AN (Cascais, 25-27.05.2006), CoimbraPorto: CEAUCP, 105-124.

—, 2011, A cultura epigráfica no conuentus Bracaraugustanus (pars occidentalis): percursos pela sociedade brácara da época romana, Coimbra: Faculdade de Letras (tese de Doutoramento apresentada à FLUC), 2 vols.

RIT = ALFÖLDY 1975.

Rodríguez Colmenero, A., 1997, Aquae Flauiae 1: Fontes epigráficas da Gallaecia meridional interior, Chaves: Câmara Municipal.

SÁ, A.M., 2007, Civitas Igaeditanorum: os deuses e os homens, Idanha-a-Nova: Município.

SiLva, A.C. F., 2011, Ordo Zoelarum: arqueologia e identidade do Nordeste de Portugal, [Bragança]: Museu do Abade de Baçal, Instituto dos Museus e da Conservaçáo.

Solin, H., Salomies, O., 1988, Repertorium nominum gentilicium et cognominum Latinorum, [Alpha-Omega: Lexika, Indizes, Konkordanzen zur klassischen Philologie, Reihe A 80], Hildesheim: Olms.

Tranoy, A., 1981, La Galice romaine, [Publications du Centre Pierre Paris 7, Collection de la Maison des pays ibériques 7], Paris: De Boccard.

Vallejo Ruiz, J.M., 2005, Antroponimia indígena de la Lusitania romana, [Anejos de Veleia. Series minor 23], Vitoria-Gasteiz: Servicio Editorial, Universidad del País Vasco.

—, 2008, «El género en la antroponimia antigua: algunas consideraciones galas e hispanas», Palaeohispanica $8,143-163$.

Vaz, F., Pereira, S., Redentor, A., 2012, «Estela funerária de Gouveia (Alfandega da Fé, Bragança)», Ficheiro Epigráfico 102, n. ${ }^{\circ} 452$.

Wiegels, R., 1985, Die Tribusinschriften des römischen Hispanien: Ein Katalog, [Madrider Forschungen 13], Berlin: Walter de Gruyter. 